ISSN 1112-9867

Available online at

http://www.jfas.info

\title{
EXAMINING THE RELATIONSHIP BETWEEN SPIRITUALITY AND ITS COMPONENTS WITH DEPRESSION IN WOMEN OF 30 TO 55 YEARS OF AGE IN AHWAZ
}

\author{
G. A. Lohranpour ${ }^{1}$, S. Chahartangi ${ }^{2, *}$ \\ ${ }^{1}$ MA studend, psychology, Islamic Azad University, Ahvaz, Iran. \\ ${ }^{2}$ MA student Family Counseling, hormozgan University, Iran.
}

Published online: 15 May 2016

\begin{abstract}
The aim of this study was to investigate the relationship between spirituality and its components (Awareness, Real Acceptance, Disappointment, Grandiosity, Instability, and Impression Management) with depression in mothers of 30 to 55 years in Ahvaz. For this purpose, 300 mothers of 30 to 55 years in Ahvaz were selected as sample through convenient method from among clients referring to hospitals, counseling centers, and parent-teacher meetings. They responded to two questionnaires of spirituality assessment by Hall and Edwards, and Depression by Beck. Hall and Edwards' spirituality questionnaire assesses six factors of Awareness, Real Acceptance, Disappointment, Grandiosity, Instability, and Impression Management. Statistical method for data analysis was multiple regression and correlation analysis. The correlation between the components of maternal depression on the one hand, and the components of spirituality on the other hand in women is calculated as $\mathrm{R}=0.600$. The results showed a significant relationship between depression and the spirituality components $(\mathrm{p}<0.05)$. The results showed that out of all different components of the research,
\end{abstract}

Author Correspondence, e-mail: author@gmail.com

doi: http://dx.doi.org/10.4314/jfas.v8i3s.284 
disappointment in the first, awareness in the second, grandiosity in the third level entered the equations, and real acceptance, grandiosity, instability, and impression management were removed from the equation. The meaningfulness of regression coefficients shows that disappointment in the equation significantly predicts depression in women, so that when the depression enters the equation, its squared correlation is 0.261 , i.e. $26.1 \%$ of the variance between maternal depression and disappointment is common.

Key words: spirituality, disappointment, depression

\section{1- INTRODUCTION}

Depression is one of the common problems in all societies, especially in our country that according to studies its prevalence in women is more than in men. According to research conducted by World Health Organization, 20\% of general population of women in developing countries suffers from depression. On the other hand, the prevalence of depression depends on several factors such as age and depression, and the studies show that the prevalence of depression in middle age and menopause is much higher. Famous psychologists like Jung, Ericsson, and Liveinsono Vilant believe that when human reaches middle of life, sees his physical and cognitive changes and multilateral pressure on himself suffers own depression and tries to rebuild the rest of his life; this thinking again is called midlife crisis that show a transition (Mansour, 2001). One of the characteristics of a successful people is acquiring the necessary skills for self-management (behavior, emotion, mentality, etc.). Due to different daily issues, persistent mental ruminations, and stressful situations that exist around most of us, the importance of managing the mind becomes evident more than ever before. In addition, by careful observation of one's inner reality, the person finds that happiness is not a quality that is dependent on external elements and changes in the outside world and happens when people let go of thoughts, having a position, and predetermined mental plans. Thus, he should let go of automated actions he does to achieve pleasure or to escape from painful situations and reach liberation (Shigakiy et al., 2006). In recent decades, scholars have dealt with the role of spirituality and religion as a method of treatment. Studies conducted from 1974 to early 1984 to gather empirical evidence on the role of spirituality and religions in 
psychotherapy in Europe have increased several times, so that people participating in religious consultation services from 1993 to early 1995 in the United States have increased several times (Worthington et al., 1996). Research shows that spiritual and religious interventions such as frequent presence in the religious ceremonies such as churches and mosques and so on are related to well-being and more internal satisfaction with life and decrease in depression (Worthington et al., 1996). Not much attention is paid to depression in women, especially mothers while depression in women can endanger family warmth, because the mothers are of the most important elements of freshness and health in each family. A woman who does not have happiness will not be successful in carrying out tasks related to parenting and relationship with spouse and family, and children in those families are affected by this kind of mood of the mother and will be disappointed and pessimistic. Several psychiatry and psychology actions are conducted in this regard, but because of complications of medicines, low pace of recovery, and recurrence of the problem that exist in majority of these treatments and methods of medication, we decided to conduct a study about the role of components of spirituality and the relationship of these features with depression in mothers. Considering that so far no research has been done specifically on women in the country, investigating the relationship of these components with depression can be an important step in the treatment of these disorders. The aim of this study is to determine the relationship between spirituality and depression in mothers of 30 to 55 in Ahvaz.

Spirituality varies from its best that has human aspect (Torsky, 1998) to search for existential meaning (Doyle, 1992) to excellence of human aspect (Martinez, 1998) (according to Bargamnt, 1999).

This is while recently authors have begun to express opposition between religion and spirituality: religion is institutional, dogmatic, and restrictive, while spirituality is personal, mental and promoting life - this type of polarization does not seem right. Empirical studies have shown that most people tend to identify themselves as religious and spiritual (Bargamnt, 1999). In addition, both religion and spirituality can be expressed individually or socially and both can accelerate or improve health (Bargamnt, 1999). In short, it should be said that there are important points in common in these two structures. Spirituality is the representative of 
the key and unique function of religion, spirituality is defined as the search for holiness (Pargament, 1999). Spirituality is the same thing people live with and breathe in its atmosphere. Mousavi Khomeini considers spirituality as the set of characteristics and actions that create passion and powerful and severe attraction yet logical and correct to make him incredibly precede on the way towards popular and unique God of the universe (Mousavi Khomeini, 1994). Motahari sees spirituality as a kind of feeling and innate tendency of human toward immaterial things such as science and knowledge, moral goodness, beauty, holiness, and worshiping that are the differences between humans and other creatures (Motahari, 1993). Some scientists believe that spirituality is derived from the Latin word spirits, which means breath of life (Beradif, 1939, Mackcoari, 1972). Moreover, Elkiz et al (1988) have investigated spirituality from the perspective of humanism and phenomenological. They believe that spirituality is derived from the Latin word "Spiritios" meaning life breath or a way of being and experiencing that is created with awareness of an unnatural aspect and determines its identifiable values (Quoted from the Arab Bafrani, 2012). These values are related to others, self, nature, and life and refer to everything that the person considers as the ultimate. However, the definition that is consistent with the approach of the present study is the one by Professor Peterson (2004) that considers spirituality as a private and intimate relationship between man and God and believes that those ranges of virtues are the signs of spirituality that look for the main life and find manifestation in a good life. Spirituality has a concept broader than religion and is essentially an experimental, personal, and fruitful process. The signs and indicators of spirituality include search for meaning, purpose, excellence (meaning that human nature is more than just a material being), relationship (relationship between nature and the universe), and values (e.g. love and justice) is (Emblen, 1998, quoting Arab Bafrani, 2012). Concepts of religion and spirituality have a lot of overlapping: both concepts may deal with issues such as searching for meaning and purpose in life may, excellence, relationships, and values. Due to many common aspects in literature, the two terms are used interchangeably in many cases. Different aspects of spirituality have a major role in the treatment of despair or disappointment as the inability to deal with stressful situations defined by feelings of confusion, worry, distress, and mental incompetence, loss of 
self-esteem, loneliness, alienation, and lack of meaning in life. Depression is identified with inability to enjoy and despair, characterized by feelings of inadequacy and helplessness. With focus on meaning control, identity, and communication components, spirituality can be combined with psychotherapy and strengthen the effectiveness of current treatments (De Souza and Rodrigo, 2004.)

In their comprehensive and valuable book on spirituality entitled powers and human virtues, while expressing the dimensions and the need to integrate them in psychotherapy, Peterson and Salimgen (2004) divided spirituality and health research into three parts:

.1Research related to assessment, measurement, and psychometric of religious scales

.2Research related to examining the importance of performance of religion and spirituality in coping with the consequences of physical and psychological disorders.

.3Research related to experiments related to cognitive and emotional aspects of religion in the form of psychotherapy models.

\section{LITERATURE REVIEW}

Being religious has experimentally shown correlation with a wide range of virtues of forgiveness, kindness, and compassion (quoted by Peterson and Seligman, 2004). Religious beliefs are one of the most influential factors in mental health and happiness of human beings. Similarly, research considers psychosocial and spiritual factors as a major step in increasing happiness. Some researchers believe that spirituality affects the psychological well-being. According to Hall and Edwards, spirituality has six subscales: Awareness, Real Acceptance, Disappointment, Grandiosity, Instability, and Impression Management (Hall and Edwards). In a study conducted by Tobern and Meyer (2010) in studying the relationship between religious beliefs and anxiety, it was found that religious people are involved in stressful assignments more and feel less anxiety during and at the end of the task (Quoted by Fattahi, 2009). In a study, the effectiveness of spiritual-religious treatment on anxiety, depression, eating disorders, alcoholism, schizophrenia, and inability to forgive was reviewed and the conclusion was that this type of treatment has been useful in treating patients (Hawk, Werthitgon et al., 2010, quoted from Fattahi, 2009). Desersire et al. (2007) conducted a study on 615 
adolescents and studied the relationship between the overall spirituality and depression at both levels, depression, and spirituality were higher in girls than in boys. Then, in the independent review, it was found that spiritual characteristics both in girls and in boys reduce the level of depression. Roby et al (2003) in a study of 118 Jewish men in New York City studied the relationship between spirituality, loneliness, and depression and after using questionnaire and studying the relationship of these variables with each other found a significant relationship between depression and loneliness $0.01>\mathrm{P}$ and a significant negative relationship was found between depression and spirituality in them. In a study of the relationship between spiritual well-being and pain and depression in 92 patients with SCI, Mazroui et al. (2014) stated that there is a negative relationship between spiritual well-being and depression at 0.05 level of significance. Jafari et al. (2012) examined the relationship between spiritual well-being and psychological hardiness with mental health of the elderly and randomly selected 100 elderly for this purpose. They administered the related questionnaire of the relationship between spiritual well-being with any of anxiety variables of social dysfunction and depression and found a significant negative relationship and positive and significant one between psychological hardiness $(\mathrm{P}<0.05)$. The results of this study have important implications about the importance of spiritual well-being and hardiness in maintaining mental health of the old. The findings of Gobari Bonab et al. (2009) on 304 students of Tehran University (124 boys and 180 girls) showed that the relationship between anxiety and depression, which are two important aspects of mental health, with its various aspects, is reverse .

Disappointment is shocking state that is identified with a sense of impossibility of affairs, inability, and disinterest in life (Schneider, 1994). According to this theory, it is assumed that the failure to achieve the objectives frequently and comprehensively reduces agency thinking, and therefore reduces hope, and this is the first phase of developing depression. From this perspective, low hope may provide the basis for depression. In depressed patients, both cognitive processes (object thinking and pathway thinking) and motivation (agency thinking) reduce. These people are less likely to be able to solve their own problems effectively. Trying to treat depression by focusing on hopeful thinking, may improve the capacity to solve problems and affective symptoms (Bahari, 2009). 


\section{METHODOLOGY}

The research method is descriptive of correlational type. The population includes women of 30 to 55 years in Ahvaz who had one or more children selected using convenient sampling method in places like hospitals, parent-teacher meetings, and counseling centers in the city. For this purpose, 300 women of 30 to 55 years in Ahvaz were asked to participate in the study by explaining the aims of the project and statistical methods used to analyze the data are Pearson correlation and multivariate regression.

\section{Measurement tool}

To collection tool in this study is questionnaire that includes two questionnaires of spirituality by Edwards Hall and depression by Beck.

\section{Spirituality assessment questionnaire}

Spirituality Assessment Questionnaire (Hall and Edwards, 1996) is designed to evaluate two aspects of spiritual growth: Knowledge of the existence of God and the quality of the relationship with God. The initial version of the test had five subscales: awareness, real acceptance, disappointment, grandiosity, and instability in 2002. Edwards and Hall revised scales and added impression management subscale to it, so the current version has six subscales. Spirituality questionnaire is a self-administered questionnaire with 47 items, some of which are composed of two parts. Participants should express their agreement or disagreement with any item in a 5-point Likert scale. Hall and Edwards (1996) reported Cronbach's alpha coefficients for the subscales of spirituality questionnaire as follows: awareness $=0.95$, disappointment $=0.90$, real acceptance $=0.83$, grandiosity $=0.73$, instability $=0.84$ and impression management $=0.77$. The coefficients showed good reliability of this test. In order to assess the validity of spirituality questionnaire, the correlations between this scale was evaluated with spiritual well-being inventory (Ellison, 1983), object relationships inventory of Bell (Bell, 1986), coping strategies questionnaire (Andrews et al., 1993); Narcissistic Personality Inventory (Raskin \& Terry, 1998), and the revised scale of internal/external motivation (Gorzokh and McPherson, 1989). The results indicate favorable construct validity of the scale. Incremental validity of spirituality questionnaire was evaluated 
by setting alienation subscale of the questionnaire of object relations by Bell as a measure of general psychological adjustment. Using a two-stage regression, the incremental validity of the test was proved.

\section{Beck's Depression Inventory}

Beck's Depression Inventory is of the most appropriate tools to reflect depression. It has 21 items scored based on Likert scoring system. The results of the meta-analysis carried out on Beck's Depression Inventory showed that the internal consistency .coefficient is between 0.73 and 0.93 with an average of 0.86

\section{The population}

Women of 30 to 55 years with one or more children, 2) Mothers

with least literacy

\section{RESULTS}

The aim of this study is to investigate the relationship between mindfulness, psychological hardiness, and spirituality with depression in mothers of 30-55 years in Ahvaz. Data from the questionnaires related to the present study were analyzed using computer software (SPSS-18). The results of statistical analysis are presented here in two separate descriptive and inferential statistics.

Table 1. Mean, standard deviation, minimum and maximum of spirituality components

\begin{tabular}{|l|l|l|l|l|l|}
\hline \multicolumn{2}{|l|}{ Variables } & Mean & $\begin{array}{r}\text { standard } \\
\text { deviation }\end{array}$ & Min & Max \\
\hline \multirow{2}{*}{$\begin{array}{l}\text { spirituality } \\
\text { components }\end{array}$} & Awareness & 70.14 & 14.96 & 27 & 90 \\
\cline { 2 - 6 } & real acceptance & 27 & 6.05 & 11 & 35 \\
\cline { 2 - 6 } & disappointment & 14.62 & 6.56 & 7 & 35 \\
\cline { 2 - 6 } & grandiosity & 19.31 & 4.62 & 11 & 34 \\
\cline { 2 - 6 } & instability & 28.25 & 6.31 & 14 & 42 \\
\cline { 2 - 6 } & impression & 15.9 & 3.48 & 7 & 25 \\
\hline & management & & & 93 & 224 \\
\hline
\end{tabular}


As can be seen in Table 1, the mean of awareness is 70.14 and standard deviation is 14.96, the mean of real acceptance is 27 and standard deviation is 6.05, mean of disappointment is 14.62 and standard deviation is 6.56 . The mean of grandiosity is 19.31 and standard deviation is 4.62, the mean of instability is 28.25 and standard deviation is 6.31 , and the mean of impression management is 15.9 and the standard deviation is 3.48. Minimum and maximum of all variables have been specified.

Mean, standard deviation, minimum, and maximum of component of depression are provided in Table 2.

Table 2. Mean, standard deviation, minimum, and maximum of component of depression

\begin{tabular}{|r|r|r|r|r|}
\hline Variable & Max & $\min$ & $\begin{array}{r}\text { standard } \\
\text { deviation }\end{array}$ & Mean \\
\hline $\begin{array}{r}\text { depression } \\
\text { components }\end{array}$ & 46 & 0 & 10.54 & 18.65 \\
\hline
\end{tabular}

As can be seen in Table 2, mean of depression components is 18.65 and standard deviation is 10.54. Minimum and maximum of all variables have been specified. 
Table 3: Pearson correlation coefficient between spirituality (Awareness, Real Acceptance, Disappointment, Grandiosity, Instability, and Impression Management) with depression in mothers

\begin{tabular}{|c|c|c|c|}
\hline \multicolumn{2}{|l|}{ Variables } & \multirow{2}{*}{$\begin{array}{c}\mathbf{R} \\
* * \ldots .14\end{array}$} & \multirow{2}{*}{$\begin{array}{r}\text { R2 } \\
16.97\end{array}$} \\
\hline \multirow{6}{*}{$\begin{array}{l}\text { depression in } \\
\text { mothers }\end{array}$} & Awareness & & \\
\hline & real acceptance & $* * \ldots .238$ & 5.66 \\
\hline & Disappointment & $* * 0.510$ & 26.01 \\
\hline & Grandiosity & $* * 0.201$ & 20.1 \\
\hline & Instability & 0.113 & 4.04 \\
\hline & Impression management & -0.241 & 5.8 \\
\hline
\end{tabular}

Table 4. Regression analysis (multiple regression)

\begin{tabular}{|c|c|c|c|}
\hline Sig & $\begin{array}{c}\text { Standard error of } \\
\text { estimate }\end{array}$ & $\begin{array}{l}\text { The squared } \\
\text { correlation }\end{array}$ & Multiple correlation \\
\hline$* * 0.001$ & 8.52 & 0.360 & 0.600 \\
\hline
\end{tabular}

Table 5. Multivariate analysis of variance (MANOVA) results for prediction of depression in mothers

\begin{tabular}{|r|r|r|r|r|r|}
\hline Source changes & Sig & F & The mean & Df & Sum of squares \\
\hline Regression & $* * 0.001$ & 27.156 & 1972.070 & 6 & $\mathbf{1 1 8 3 2 . 4 1 9}$ \\
\hline remained & - & - & 72.621 & 290 & $\mathbf{2 1 0 6 0 . 0 5 0}$ \\
\hline Total & - & - & - & $\mathbf{2 9 6}$ & $\mathbf{3 2 8 9 2 . 0 4 7}$ \\
\hline
\end{tabular}


As shown in Table 5, the results of analysis of variance have confirmed the reliability of the regression analysis done to predict depression in mothers by research variables $(\mathrm{F}=27.156$, $\mathrm{P}<0.001)$.

\section{CONCLUSION AND RECOMMENDATIONS}

The results in Table 2 state a positive multiple relationship between characteristics of spirituality (Awareness, Real Acceptance, Disappointment, Grandiosity, Instability, and Impression Management) with depression in mothers. Here the correlation between depression of mothers on the one hand, and the different components of spirituality component (Awareness, Real Acceptance, Disappointment, Grandiosity, Instability, and Impression Management) on the other hand is calculated as $\mathrm{R}=0.600$. This correlation is called multiple correlation.

If this coefficient gets exponent two, it becomes 0.360 and shows that $36 \%$ of the variance or individual differences in the components of depression in mothers are related to variance or individual differences in the different components of spirituality (Awareness, Real Acceptance, Disappointment, Grandiosity, Instability, and Impression Management). The results showed that out of all different components of the research, disappointment in the first, awareness in the second, grandiosity in the third level entered the equations, and real acceptance, grandiosity, instability, and impression management were removed from the equation. The significance of the regression coefficients indicates that disappointment in equation significantly predicts the component of depression in mothers. As can be seen, when disappointment enters the equation, its square of the correlation is 0.261 . This means $26.1 \%$ of the variance between depression in mothers and disappointment components is common. With the addition of awareness and grandiosity, prediction power increased to 35.4 percent. Real acceptance, grandiosity, instability, and impression management due to overlap with other variables have been removed from the equation. In total, according to standardized beta coefficients, it is seen that disappointment with 0.354 , awareness with 0.298 , and grandiosity with 0.254 have the most significant effect in explaining the changes and predicting depression in mothers. This finding is consistent with research by Mazrai et al. (2014), Jafari 
et al. (2012), Ghobari Bonan (2009), Tobern and Meyer (2010), Desersire et al. (2007), and Robbie et al. (2003). In general, it can be stated that, spirituality is an aspect of human that shows his communication and integration with the universe. Communication and integration give human hope and meaning and take him beyond the limits of time and space and unity in being is seen by spiritual people. Religion and spirituality offer a set of words and frameworks through which, people can understand the meaning of their life. State of mental relaxation, relaxation and comfort due to religious issues are thus because the individual consciously and sincerely loves them.

\section{REFERENCES}

1. Arab Bafrani, H.R. Comparing the effectiveness of teaching spirituality and Neuro-linguistic programming training on marital fitness of couples referring to counseling centers in Isfahan, Master's thesis, Isfahan, 2012.

2. Bagherighobari, M. Motavali Pour, A. Habibi, M. The relationship of anxiety and depression in students of Tehran University, Quarterly of Applied Psychology, 2009, 3, 2 (10) : 123-110

3. Bahari, F. Comparing the effect of marital counseling on hope and combined forgiveness model and hope interpersonal cognitive distortions and contradictions of married couples referring to counseling centers in Isfahan, $\mathrm{PhD}$ dissertations, Department of Counseling, School of Psychology, University of Isfahan, 2009.

4. Dehshiri, Gh, Sohrabi, F., Jafari, I. Najafi, M, Studying characteristics: psychometric of spiritual well-being scale among students, Psychological Studies, 2008, 16.

5. Desrosiers. Alethea and Lisa Miller. Relational spirituality and depression in adolescent girls, Journal of Clinical Psychology, Special Issue: Special Issue on Spirituality and Psychotherapy 2007, 63, 10 : pages 1021-1037.

6. D’Souza, R., \& Rodrigo, A. Spiritually augmented cognitive Behavioural therapy. Australas Psychiatry, 2004, 12, 148-152. 
7. Pargament.k.1 .Religious and prevention in mental health. Research Division and action.Haworth press. Inc, 1995

8. Ebrahimimehr, H. The relationship between emotional intelligence and spirituality in the workplace and organizational citizenship behavior in four areas of education staff Qom, Master's thesis, General Psychology, Isfahan University, 2011.

9. Fattahi, R. Studying effectiveness of spiritual healing Islamists groups of dysthymic symptoms and quality of life Isfahan University Students, MA thesis, Isfahan University, 2010.

10. Jafari, I, Hajloo, N. Faghani, R. Khazan, K. The relationship of spiritual well-being and psychological hardiness and mental health of the elderly, the Journal of Research in Behavioural Sciences, 2012, I (6).

11. Motahhari, M. Introduction to the monotheistic worldview, Tehran: Sadra, $1993:$ p 7

12. Mazrui, A.H Amanullahfar, $M$ and A. The relationship between spiritual well-being and depression in people with spinal cord injury pain, First National Conference on Educational Sciences spirituality and health psychology Bandar Gaz, Islamic Azad University, Gaz, 2014.

13. Mazaheri, M. Studying the attitude to spirituality spiritual care in Razi psychiatric nurses Medical Center and offering training plan. Mental Rehabilitation Administration of Social Welfare Prstary.danshgah master's thesis, 2005.

14. Mousavi Khomeini, R.A. Forty Hadith, Ch 13, Qom, Institute for Compilation and Publication of Imam Khomeini's Works, 1994.

15. Mansour, M. Genetic Psychology, SAMT Publications, 2001.

16. Najarian, B. (). Psychology of anxiety, Scientific Journal of University of Ahvaz, 2001, (1 and 2) : 83-65.

17. Nejati, M.A Quran and psychology, translations by Abbas Arab, Mashhad, Islamic Foundation research publication, 1989. 
18. Rabbi Mychal.AnderwJ.weaver. Larry v and e creek. Spirituality, Depression, and loneliness Amongjewish seniors residing in New York city. The Journal of pastoral care \& counseling, 2003, 57 No.3

19. Snyder. C.R. The Psychological of HOPE: You can get there from here. NEW YORK: Free press, 1994.

20. Shigaki CL, Glass B, Schopp LH Mindfulness based stress reduction in medical settings. J ClinPsychol Med Settings; 2006, 13(3): 209-15.

21. Seligman , Martin and Peterson , Christopher. character strengths and Virtues.oxford University press, 2004.

22. Tubren T, Meier BP. Priming God-Related Concepts Increases Anxiety and Task Persistence. J Soc Clin Psychol. 2010;29(2):127-1421.

23. Safairad, I., Karimi, L. Shamusi, N.A. Ahmaditahur, M, The relationship between spiritual well-being and mental health of students, Journal of University of Medical Sciences and Health Services274. 280: Sabzevar, 2010, 17(4).

24. Vest, W Psychotherapy and Spirituality, Translation by Shahidi, Shahriar, Shirafkan, Soltanali (first edition) Roshd Publications, 2004.

25. Werthington Malice, tolerance, religion and health, Criticism and opinion magazine 2011, 9,1 and 2.

26. Worthington EL, JR Kurusu TA, McCullough ME, SandageSJ. Empirical research on religion and research on religion and Psychotherapeutic processes and outcome: A 10-year review and research prospectus. Psychological Bulletin; 1996, 119: 448-87.

\section{How to cite this article:}

Lohranpour A G, Chahartangi S. Examining the relationship between spirituality and its components with depression in women of 30 to 55 years of age in ahwaz. J. Fundam. Appl. Sci., 2016, 8(3S), 1374-1387. 